\title{
Optimal waist circumference cut-off points for predicting metabolic syndrome among low-income black South African adults
}

\author{
Eyitayo Omolara Owolabi ${ }^{*} \mathbb{B}$, Daniel Ter Goon ${ }^{1}$, Oladele Vincent Adeniyi ${ }^{2}$ and Anthony Idowu Ajayi ${ }^{3}$
}

\begin{abstract}
Objective: Waist circumference has been identified as one of the strongest predictive tool for metabolic syndrome. This study determines the optimal cut-off point of waist circumference for metabolic syndrome among low-income earning South African black population, in Eastern Cape, South Africa. The optimal waist circumference cut-off point was determined through receiver operating characteristics analysis using the maximum Youden index.

Results: Among men, waist circumference at a cut-off value of $95.25 \mathrm{~cm}$ yielded the highest Youden index of 0.773 (sensitivity $=98 \%$, specificity $=79 \%$, area under curve 0.893). For women, waist circumference of $89.45 \mathrm{~cm}$ yielded the highest Youden index of 0.339 (sensitivity $=88 \%$, specificity $=46 \%$, area under curve 0.713 ). The prevalence of metabolic syndrome among men, women and both sexes using the new cut-off points were: 17.8, 20.8 and 17.7\%, respectively, compared to; 15.6, 24.8 and $21.8 \%$, using the traditional cut-off values of 94 and $80 \mathrm{~cm}$ for men and women, respectively. The traditional waist circumference value slightly under-estimated the prevalence of metabolic syndrome among men and over-estimated among women and the overall population. A specific waist circumference cut-off point for South African blacks is needed for correct identification of the metabolic state of the populace in order to develop appropriate interventions.
\end{abstract}

Keywords: Metabolic syndrome, Abdominal obesity, ROC curves, Youden index, Africans, South Africans

\section{Introduction}

Metabolic syndrome (METs) is characterized by clustering of metabolic abnormalities such as central obesity, hypertension, dyslipidemia, and glucose intolerance [1]. It is an essential public health challenge as a result of its association with cardiovascular disease, a leading cause of morbidity and mortality [2]. The waist circumference (WC) has been identified as one of the strongest predictive tool for METs. This anthropometric indicator is easy, inexpensive and non-invasive and can be applied in clinical practice. However, due to the absence of country specific WC cut-offs, the validated WC cut-points ( $\geq 94 \mathrm{~cm}$ in men and $\geq 80 \mathrm{~cm}$ in women) for European populations are presently being utilised by researchers

\footnotetext{
*Correspondence: owolabiomolara101@gmail.com

1 Department of Nursing Science, Faculty of Health Sciences, University of Fort Hare, East London, South Africa

Full list of author information is available at the end of the article
}

and clinicians in screening for abdominal obesity in African and African-descent individuals [3]. This is not optimal, as dichotomy exist in the pattern of fat distribution between Caucasians and black Africans [4, 5]. Also, several studies have suggested that the METs as currently defined may not be appropriate to predict cardiovascular disease and type 2 diabetes risk in Africans [6-8]; as Black Africans exhibit more propensity to insulin resistance, and a higher prevalence of hypertension and low high density lipoprotein cholesterol (HDL-C) levels, in contrast to lower rates of hypertriglyceridemia compared to the Caucasians $[9,10]$.

Controversies exist concerning the correct anthropometric values relative to ethnicity, genetic background, sex, and sociocultural context [11]. Studies have shown that WC is among the most powerful tools for predicting METs and that the optimal cut-off values for various indices, including WC, may differ by sex and race [1216]. Studies investigating the WC cut-points of METs for 
Africans are rare, and have reported inconsistent results [17-19]. Additionally, such studies in the South African context are conducted in high-income and urban settings [17, 19-23]; while only few studies are reported in low-income, rural settings [18, 24]. We sought to determine the optimal cut-point of WC for METs among lowincome earning, rural South African black population, using the cardiometabolic screening data of out-patients attending health facilities in Buffalo City Metropolitan Municipality, Eastern Cape, South Africa.

\section{Main text \\ Methods}

Detailed accounts of the sampling procedures for cardiometabolic screening data have been published elsewhere [25-27]. Briefly, this cardiometabolic screening survey was conducted at the three largest out-patient clinics in the largest settlement in Buffalo City Metropolitan Municipality, South Africa. A sample size of 1107 participants was estimated across the three study sites (369 per site), based on the estimated non-communicable disease prevalence rate of $40 \%$ in South Africa, with a sampling error of 5 and a 95\% confidence level. Due to incomplete data, 109 participants were excluded, thus, only 998 adults (321 males, 627 females) were included in the analysis. Eligibility criteria included age $\geq 18$ years, attendance at the out-patient clinics, and $8 \mathrm{~h}$ of fasting prior to recruitment into the study. Patients who were psychotic, debilitated, pregnant or handicapped in any form to the point that obtaining anthropometric measurement would be difficult were excluded from the study. All ambulatory individuals who fulfilled the inclusion criteria and attended the study settings during the period of study were recruited into the study. This study was conducted in April and May, 2016. A convenience sampling method was utilised.

Participants were interviewed using the previously validated WHO STEPwise questionnaire which comprises three major items; demographic data, behavioural data and measurements. The questionnaire was written in english. Interview was conducted by trained research assistants and both anthropometric and blood pressure measurements were done by trained professional nurses. Waist circumference, blood pressure and fasting blood glucose measurements followed standardised protocols. Metabolic syndrome was defined using the International Diabetes Federation (IDF) criteria as the presence of any three of the following five criteria; high blood pressure, diabetes, prediabetes, high cholesterol and abdominal obesity [28].

Data were analysed using Statistical Package for Social Sciences (SPSS) software, version 23.0 (SPSS Inc. Chicago, IL). The optimal WC cut-point was determined through Receiver Operating Characteristics (ROC) curve analysis using the Youden index [maximum (sensitivity + specificity -1 )] [29]. Waist circumference was excluded from the classification of METs, because it was an outcome variable for developing cut-points. Previous studies have used two or more components other than WC to classify METs in South Africa [18, 22]. Analysis was done at a confidence interval of 95\%. A p $<0.05$ was considered statistically significant.

\section{Results}

The mean age of participants was $42.6(\mathrm{SD} \pm 16.5)$ years. The majority of the participants were black (98.1\%), female $(67.8 \%)$, single $(63.9 \%)$ and had at least secondary (grade 8) level of education (69.7\%). About half of the participants had no income (44.6\%) and were unemployed (47.7\%), while only a few (7.5\%) participants earned above 400USD monthly (Additional file 1: Table S1).

Among men, $\mathrm{WC}$ at a cut-off value of $95.25 \mathrm{~cm}$ yielded the highest Youden index (0.773) with a corresponding sensitivity of $98 \%$ and specificity of $79 \%$ [area under the ROC curve (AOC) $0.893, \mathrm{p}<0.001,95 \%$ confidence interval (CI) 0.858-0.928]. At the traditional cutoff value of $94 \mathrm{~cm}$, the Youden index slightly dropped to 0.74 , with sensitivity and specificity remaining the same. For women, the WC at a cut-off value of $89.45 \mathrm{~cm}$ yielded the highest Youden index (0.339) with a sensitivity of $88 \%$ and specificity of $46 \%$ (AOC 0.713 , p $<0.001$, 95\% CI 0.673-0.753). At the traditional cut-off value of $80 \mathrm{~cm}$, the Youden index dropped to 0.249 with a corresponding increase in sensitivity to $100 \%$ and a significant reduction in specificity to $25 \%$ (Fig. 1 ). The prevalence of METs among men, women and both sexes using the new cut-points (WC $\geq 95.25 \mathrm{~cm}$ for men and $\geq 89.45 \mathrm{~cm}$ for women) were: $17.8,20.8$ and $17.7 \%$, respectively, compared to; $15.6,24.8$ and $21.8 \%$, using the traditional cut-off values of 94 and $80 \mathrm{~cm}$ for men and women, respectively (Fig. 2).

\section{Discussion}

To the best knowledge of the authors, this is the first study to determine the optimal WC cut-points for predicting METs among low-income black South African adults in the Eastern Cape region. An earlier study reported a WC of $91.5 \mathrm{~cm}$ in diagnosing METs among urban South African women in Soweto [17]; while another study reported a WC of $92 \mathrm{~cm}$ as optimal for women [18]; and yet, a WC of $98 \mathrm{~cm}$ for African women has been reported [19]. In this present study, the prevalence of METs among men, women and both sexes using the new cut-off points (WC $\geq 95.25 \mathrm{~cm}$ for men and $\geq 89.45 \mathrm{~cm}$ for women) were: $17.8,20.8$ and $17.7 \%$, respectively, compared to; $15.6,24.8$ and $21.8 \%$, using the 


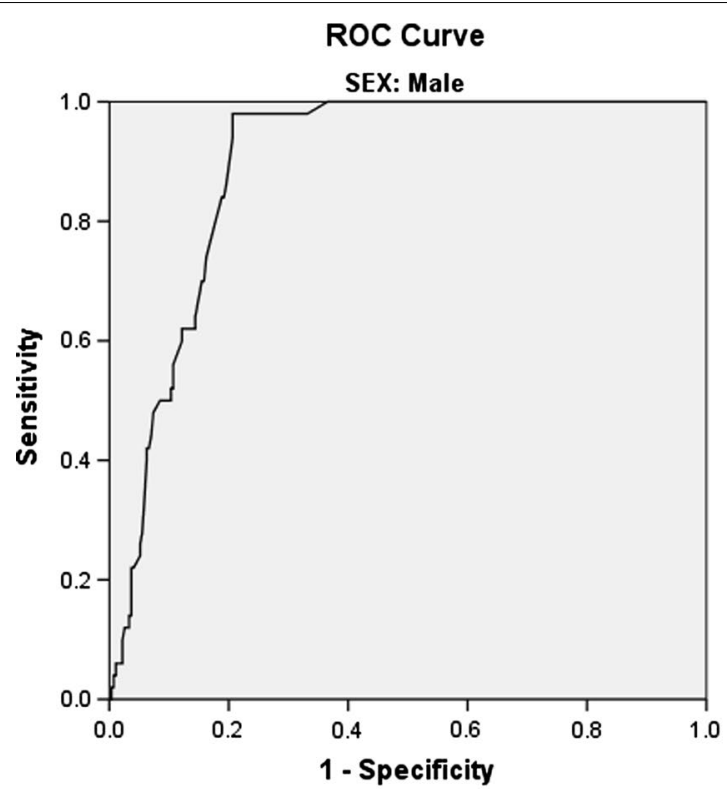

Diagonal segments are produced by ties.

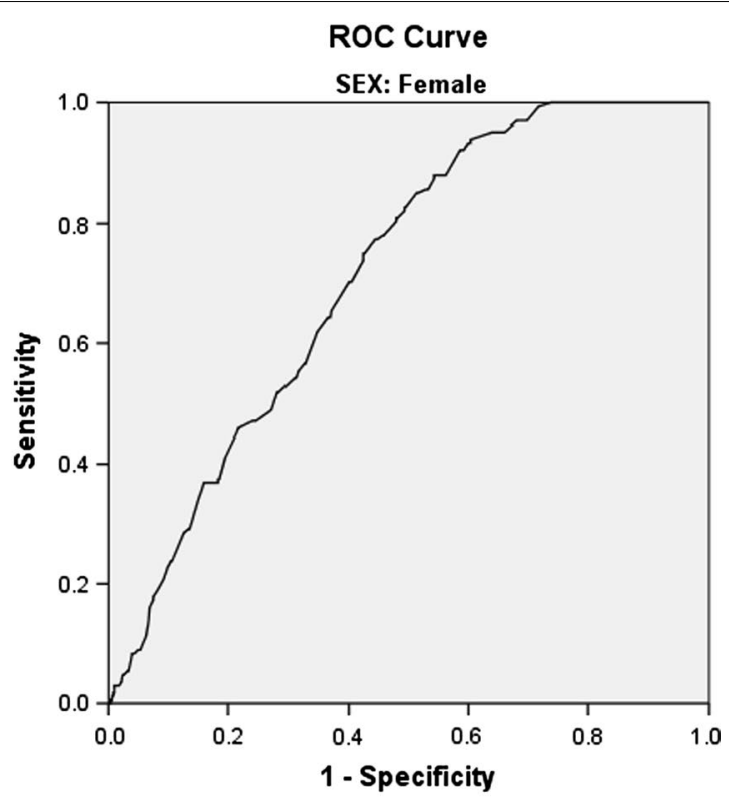

Diagonal segments are produced by ties.

Fig. 1 ROC curve for waist circumference as a predictor of metabolic syndrome among men and women

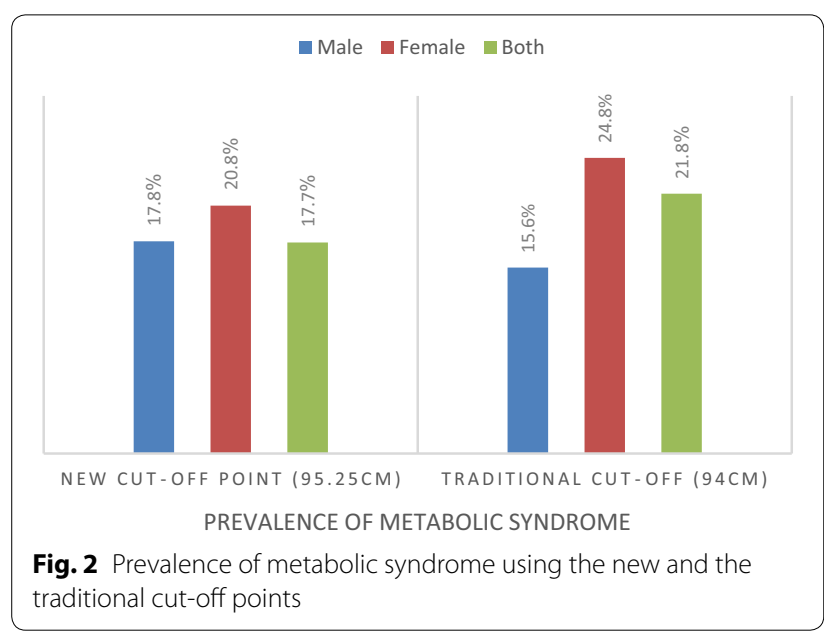

traditional cut-off values of $94 \mathrm{~cm}$ and $80 \mathrm{~cm}$ for men and women, respectively. This confirms the inconsistencies in WC cut-points in different races and sexes as reported in the literature [12-16]. The optimal cut-point of WC for the diagnosis of metabolic syndrome is distinct in different African countries (Table 1).

Notwithstanding the differences in defining METs, the WC cut-off points are persistently high in African women. This could be explained by the high prevalence of obesity among women compared to men in the African societies, shaped by socio-economic and environmental variables. Given that women have higher proportion
Table 1 Comparison of optimal cut-off point of waist circumference (WC) for the diagnosis of metabolic syndrome in African countries with the present study

\begin{tabular}{lrll}
\hline $\begin{array}{l}\text { Country [refer- } \\
\text { ences] }\end{array}$ & $\mathbf{n}$ & $\begin{array}{l}\text { Cut-off point } \\
\text { for men }(\mathbf{c m})\end{array}$ & $\begin{array}{l}\text { Cut-off point } \\
\text { for women (cm }\end{array}$ \\
\hline Uganda [24] & 6136 & $\geq 78$ to $\geq 80$ & $\geq 82$ to $\geq 85$ \\
South Africa [19] & 123 & 90 & 98 \\
Nigeria [36] & & 76 & 72 \\
Cameroon [36] & & 81 & 82 \\
Benin [23] & 452 & 80 & 94 \\
Angola [31] & 615 & 87.5 & 80.5 \\
South Africa [18] & 947 & 86 & 92 \\
Benin [37] & 541 & 80 & 90 \\
South Africa [17] & 1251 & 91.5 & \\
South Africa [21] & 152 & 92 & 94 \\
South Africa [38] & 1099 & 84 & 94 \\
South Africa [22] & 920 & 87.5 & 94.6 \\
South Africa [20] & 203 & $\geq 88$ or $\geq 90$ & - \\
South Africa (present & 998 & $\geq 95.25$ & $\geq 89.45$ \\
$\quad$ study) & & & \\
\hline
\end{tabular}

of total subcutaneous fat distribution compared to men [30], the potential risk of misclassification of women as having excessive visceral adiposity by using values of WC to predict other components of the METs [31], cannot be ignored. Conversely, Lemieux [32] and Alberti [33] reports a low WC cut-off in men compared to women, which was attributed to the notion that on average, men 
have twice as much visceral abdominal fat than premenopausal women [32].

Notably, consistent with our study, the waist WC cutpoint currently being utilised for the diagnosis of METs in sub-Saharan African females $(80 \mathrm{~cm})[34,35]$ is too low and will therefore over-estimate the prevalence of METs. As such, there is need to validate the $\mathrm{WC} \geq 95.25 \mathrm{~cm}$ for men and $\geq 89.45 \mathrm{~cm}$ for women observed in this present study for other sub-Saharan African populations. Country, ethnic-and gender-specific WC cut-off points are needed, because adopting other WC criteria to diagnose African black populations may either under-or overestimate the presence of METs.

As pointed by Murphy et al. [24], optimal ethnic-specific WC cut-off points are seemingly useful as a screening tool that provides benefits in the detection of obesity and assessing the risks of other related diseases such as diabetes and cardiovascular disease. Viewed in this perspective, the findings from this prospective study provide up-to-date, evidence-based data that can be utilised for public health interventions in low-income populations, at least among underserved black Africans, in this setting.

\section{Conclusion}

The traditional waist circumference value used for the diagnosis of metabolic syndrome may not be suitable for this study participants as it might have slightly underestimated the prevalence of METs among men and overestimated the prevalence of METs among the women and the overall population. There is a need to determine a specific WC cut-off point for South African blacks as this will assist in correctly identifying the metabolic state of the populace and develop appropriate interventions.

\section{Limitations}

Using measured anthropometric variables, as opposed to self-reported values, in a relatively large sample with very reliable data are the main strengths of this study. The limitations of the study should be noted.

- Due to the cross-sectional nature of the study, we therefore cannot infer causality. The WC cut-off points proposed by our study need to be confirmed in a longitudinal study.

- In addition, we did not measure the lipid levels in the study sample which might have underestimated the burden of METs in the setting.

\section{Additional file}

Additional file 1: Table S1. Demographic characteristics of the study participants.

\section{Abbreviations}

WC: waist circumference; METs: metabolic syndrome; HDL: high-density lipoprotein; ROC: receiver operating characteristics; AOC: area under receiver operating characteristics curve; IDF: International Diabetes Federation.

\section{Authors' contributions}

EOO, DTG and OVA conceptualised, designed and drafted the paper. AIA analysed the data and gave intellectual contribution into the manuscript. All authors read and approved the final manuscript.

\section{Author details \\ ${ }^{1}$ Department of Nursing Science, Faculty of Health Sciences, University of Fort Hare, East London, South Africa. ${ }^{2}$ Department of Family Medicine, Faculty of Health Sciences, Walter Sisulu University, Cecilia Makiwane Hospital, East London Hospital Complex, East London, South Africa. ${ }^{3}$ Department of Sociol- ogy, Faculty of Social Science and Humanities, University of Fort Hare, East London, South Africa.}

\section{Acknowledgements}

A poster presentation of the abstract of this study was made at the 21 st International Epidemiological Association World Congress of Epidemiology held from 18th to 22nd of August, 2017 in Saitama, Japan.

\section{Competing interests}

The authors declare that they have no competing interests.

Availability of data and materials

Data from this study will be made available on request.

\section{Consent for publication}

Not applicable.

\section{Ethics approval and consent to participate}

Ethical approval was obtained in accordance with the Helsinki II Declaration from the University of Fort Hare Research Ethics Committee and the Eastern Cape Department of Health (Reference Number; GOO061SOLO01). The management of the sub-district Department of Health as well as the heads of the respective health facilities gave permission prior to data collection. All participants provided written informed consent to participate in this study. Anonymity and confidentiality were ensured.

Funding

EOO receive financial support from the National Research Foundation of South Africa and the Health and Welfare Sector Education and Training Authority, South Africa for her master's degree from which this study emanated.

\section{Publisher's Note}

Springer Nature remains neutral with regard to jurisdictional claims in published maps and institutional affiliations.

Received: 13 October 2017 Accepted: 6 January 2018

Published online: 12 January 2018

\section{References}

1. Al-Thani MH, Al-Thani AAM, Cheema S, Sheikh J, Mamtani R, Lowenfels $A B$, et al. Prevalence and determinants of metabolic syndrome in Qatar: results from a national health survey. BMJ Open. 2016;6:e009514.

2. Ford ES. Risks for all-cause mortality, cardiovascular disease, and diabetes associated with the metabolic syndrome: A summary of the evidence. Diabetes Care. 2005;28:1769-78.

3. World Health Organisation. Waist circumference and waist-hip ratio report of a WHO Expert Consultation. Geneva: World Health Organisation; 2011.

4. Katzmarzyk PT, Bray GA, Greenway FL, Johnson WD, Johnson WD, Newton RL Jr, Ravussin E, et al. Racial differences in abdominal depot-specific 
adiposity in white and African American adults. Am J Clin Nutr. 2010;91(1):7-15.

5. Desiles MC, Garrel D, Couillard C, Tremblay A, Després JP, Bouchard C, et al. Ethnic differences in body composition and other markers of cardiovascular disease risk: study in matched Haitian and White subjects from Quebec. Obesity. 2016;14(6):1019-27.

6. Delisle H, Desilets MC, Vargas ER, Garrel D. Metabolic syndrome in three ethnic groups using current definitions. Appl Physiol Nutr Metab. 2008;33(2):356-60.

7. Longo-Mbenza B, Kasiam-Lasi OJB, Nge Okwe A, Kangola KN. The metabolic syndrome in a Congolese population and its complications for metabolic syndrome definitions. Diabetes Metab Syndr. 2011;5(1):17-24.

8. Ukegbu UJ, Castillo DC, Knight MG, et al. Metabolic syndrome does not detect metabolic risk in African men living in the US. Diabetes Care. 2011;34(10):2297-9.

9. Gaillard T, Schuster D, Osei K. Differential impact of serum glucose, triglycerides, and high-density lipoprotein cholesterol on cardiovascular risk burden in nondiabetic obese African American women: implications for the prevalence of metabolic syndrome. Metabolism. 2010;59(8):1115-23.

10. Schuster DP, Gaillard T, Osei K. The cardio-metabolic syndrome in persons of the African diaspora: challenges and opportunities. J Cardiometab Syndr. 2007;2(4):260-6.

11. He J, Ma R, Liu J, et al. The optimal ethnic-specific waist-circumference cut-off points of metabolic syndrome among low-income rural Uyghur adults in Far western China and implications in preventive public health Int J Environ Res Public Health. 2017;14:15.

12. Beydoun MA, Kuczmarski MTF, Wang Y, et al. Receiver-operating characteristics of adiposity for metabolic syndrome: The Healthy Aging in Neighborhoods of Diversity across the Life Span (HANDLS) study. Public Health Nutr. 2011;14:77-92.

13. Gharipour M, Sarrafzadegan N, Sadeghi M, et al. Predictors of metabolic syndrome in the Iranian population: waist circumference, body mass index, or waist to hip ratio? Cholesterol. 2013. https://doi. org/10.1155/2013/198384.

14. Bener A, Yousafzai MT, Darwish S, et al. Obesity index that better predict metabolic syndrome: Body mass index, waist circumference, waist hip ratio, or waist height ratio. J Obes. 2013. https://doi. org/10.1155/2013/269038.

15. Lee JJ, Ho C, Chen HJ, et al. Is the 90th percentile adequate? The optimal waist circumference cutoff points for predicting cardiovascular risks in 124,643 15-year-old Taiwanese adolescents. PLoS ONE. 2016;11:e0158818.

16. Katzmarzyk PT, Bray GA, Greenway FL, et al. Ethnic-specific BMI and waist circumference thresholds. Obesity (Silver Spring). 2011;19:1272-8.

17. Crowther NJ, Norris SA. The current waist circumference cut point used for the diagnosis of metabolic syndrome in Sub-Saharan African women is not appropriate. PLoS ONE. 2012;7(11):e48883. https://doi.org/10.1371/ journal.pone.0048883.

18. Motala AA, Esterhuizen T, Pirie FJ, et al. The prevalence of metabolic syndrome and determination of the optimal waist circumference cut-off points in a rural South African community. Diabetes Care. 2011;34:1032-7.

19. Prinsloo J, Malan L, de Ridder JH, et al. Determining the waist circumference cut off which best predicts the metabolic syndrome components in urban Africans: the SABPA study. Exp Clin Endocrinol Diabetes. 2011;119:599-603.

20. Kalk WJ, Joffee BI, Sumner AE. The waist circumference of risk in Black South African Men is lower than in Men of European Ancestry. Metab Syndr Relat Disord. 2011;9(6):491-5.

21. Hoebel S, Malan L, Botha J, Swanepoel M. Optimizing waist circumference cut-points for the metabolic syndrome in a South African Cohort at 3-year follow-up: the SABPA prospective cohort. Endocrine. 2014:47:959-61.
22. Matsha TE, Hassan MS, Hon GM, Soita DJ, Kegne AP, Erasmus RT. Derivation and validation of a waist circumference optimal cut-off for diagnosing metabolic syndrome in a South African mixed ancestry population. Int J Cardiol. 2013;168(3):2954-5.

23. Mabchour AEL, Delisle H, Vilgrain C, Larco P, Sodjinou R, Batal M. Specific cut-off points for waist circumference and waist-to-height ratio as predictor of cardiometabolic risk in Black subjects: a cross-sectional study in Benin and Haiti. Diab Metab Syndr obes. 2015;8:513-23.

24. Murphy GAV, Asiki G, Nsubuga RN, Young Ah, Maher D, Seeley J, et al. The use of anthropometric risk identification in rural African population. Diabetes Care. 2014;37:e64-5.

25. Owolabi EO, Goon DT, Adeniyi OV, Seekoe E. Correlates of pre-diabetes and Type 2 diabetes in Buffalo City Municipality, South Africa. AJPHES. 2016;22(41):1019-35.

26. Owolabi EO, Goon DT, Adeniyi OV, Seekoe E. Social epidemiology of hypertension in Buffalo City Metropolitan Municipality (BCMM): crosssectional study of determinants of prevalence, awareness, treatment and control among South African adults. BMJ Open. 2017;7:e014349.

27. Owolabi EO, Goon DT, Adeniyi OV, Adedokun AO, Seekoe E. Prevalence and associated factors of obesity among South African adults: a crosssectional study. Online J Health Allied Sci. 2017;16(2):1.

28. International Diabetes Federation. The IDF consensus worldwide definition of the metabolic syndrome. Brussels: Belgium; 2006.

29. Youden WJ. An index for rating diagnostic tests. Cancer. 1950;3:32-5.

30. Owolabi EO, Goon DT, Adeniyi OV, Adedokun AO, Seekoe E. Prevalence and correlates of metabolic syndrome among adults attending healthcare facilities in Eastern Cape, South Africa. Open Public Health J. 2017;10:63-8.

31. Hayashi T, Boyko EJ, McNeely MJ, Leonetti DL, Kahn SE, Fujimoto WY. Minimum waist and visceral fat values for identifying Japanese Americans at risk for the metabolic syndrome. Diabetes Care. 2007;30(1):120-7.

32. Magalhaes P, Capingana DP, Mill JG. Prevalence of the metabolic syndrome and determination of optimal cut-off values of wasit circumference in university employees from Angola. Cadiovasc J Afr. 2014;25(1):27-33.

33. Lemieux S, Prud'homme D, Bouchard C, Tremblay A, Despres JP. Sex differences in the relation of visceral adipose tissue accumulation to total body fatness. Am J Clin Nutri. 1993;58:463-7.

34. Alberti KG, Eckel RH, Grundy SM, International Diabetes Federation Task Force on Epidemiology and Prevention; National Heart, Lung, and Blood Institute; American Heart Association; World Heart Federation; International Atherosclerosis Society; International Association for the Study of Obesity, et al. Harmonizing the metabolic syndrome: a joint interim statement of the International Diabetes Federation Task Force on Epidemiology and Prevention; National Heart, Lung, and Blood Institute; American Heart Association; World Heart Federation; International Atherosclerosis Society; and International Association for the Study of Obesity. Circulation. 2009;120:1640-5.

35. Alberti KG, Zimmet P, Shaw J, IDF, Epidemiology Task Force Consensus Group. The metabolic syndrome-a new worldwide definition. Lancet. 2015;366:1059-62.

36. Okosun IS, Liao Y, Rotimi CN, Prewitt TE, Cooper RS. Abdominal adiposity and clustering of multiple metabolic syndrome in White, Black and Hispanic Americans. Ann Epidemiol. 2000;10(5):263-70.

37. Agueh VD, Sossa C, Ouendo DME, Paraizo NM, Azandjemè C, Kpozehouen $A$, et al. Determination of the optimal waist circumference cut-off points in Benin adults. Open J Epidemiol. 2015;5:217-28.

38. Peer N, Lombard C, Steyn K, Levitt N. High prevalence of metabolic syndrome in the Black population of Cape Town: the cardiovascular risk in Black South Africans (CRIBSA) study. Eur J Prev Cardiol. 2015;22(8):1036-42. 